\title{
What have we learned from a systematic review of literature on Hispanic transfer students in engineering?
}

\author{
Dr. Jeffrey E. Froyd, Texas A\&M University
}

Dr. Jeffrey E. Froyd is a TEES Research Professor in the Office of Engineering Academic and Student Affairs at Texas A\&M University, College Station. He received the B.S. degree in mathematics from Rose-Hulman Institute of Technology and the M.S. and Ph.D. degrees in electrical engineering from the University of Minnesota, Minneapolis. He was an Assistant Professor, Associate Professor, and Professor of Electrical and Computer Engineering at Rose-Hulman Institute of Technology. At Rose-Hulman, he co-created the Integrated, First-Year Curriculum in Science, Engineering and Mathematics, which was recognized in 1997 with a Hesburgh Award Certificate of Excellence. He served as Project Director a National Science Foundation (NSF) Engineering Education Coalition in which six institutions systematically renewed, assessed, and institutionalized innovative undergraduate engineering curricula. He has authored over 70 papers and offered over 30 workshops on faculty development, curricular change processes, curriculum redesign, and assessment. He has served as a program co-chair for three Frontiers in Education Conferences and the general chair for the 2009 conference. Prof. Froyd is a Fellow of the IEEE, a Fellow of the American Society for Engineering Education (ASEE), an ABET Program Evaluator, the Editor-inChief for the IEEE Transactions on Education, a Senior Associate Editor for the Journal of Engineering Education, and an Associate Editor for the International Journal of STEM Education.

\section{Dr. Julie P Martin, Clemson University}

Julie P. Martin is an assistant professor of Engineering and Science Education at Clemson University. Her research interests focus on social factors affecting the recruitment, retention, and career development of underrepresented students in engineering. Dr. Martin is a 2009 NSF CAREER awardee for her research entitled, "Influence of Social Capital on Under-Represented Engineering Students Academic and Career Decisions." She held an American Association for the Advancement of Science (AAAS) Science and Technology Policy Fellowship in 2013-2014, with a placement at the National Science Foundation.

\section{Dr. Maura J. Borrego, University of Texas, Austin}

Maura Borrego is Associate Professor of Mechanical Engineering and Curriculum \& Instruction at the University of Texas at Austin. She previously served as a Program Director at the National Science Foundation and an associate dean and director of interdisciplinary graduate programs. Her research awards include U.S. Presidential Early Career Award for Scientists and Engineers (PECASE), a National Science Foundation CAREER award, and two outstanding publication awards from the American Educational Research Association for her journal articles. Dr. Borrego is an Associate Editor for Journal of Engineering Education and serves on the board of the American Society for Engineering Education as Vice President for Professional Interest Councils and Chair of Professional Interest Council IV. All of Dr. Borrego's degrees are in Materials Science and Engineering. Her M.S. and Ph.D. are from Stanford University, and her B.S. is from University of Wisconsin-Madison.

\section{Mr. Hyung Sok Choe, The University of Texas at Austin}

Hyung Sok Choe is a doctoral student in STEM education at UT Austin. His research focuses on the curriculum and assessment design of project based learning for online based engineering courses and the development of engineering identity. Hyung Sok holds a master's degree in electrical engineering from Illinois Tech.

\section{Mrs. Margaret J. Foster, Texas A\&M University}

Margaret J. Foster is the Systematic Reviews Coordinator and Associate Professor at the Medical Sciences Library at Texas A\&M University. With over 10 years experience in conducting and consulting on systematic reviews, she has contributed to hundreds of theses, dissertations, and publications across several disciplines. 


\section{Ms. XUESHU CHEN, University of Texas at Austin}

Xueshu Chen is a doctoral student in information studies at UT Austin. Her research interests primarily include broadening participation of underrepresented groups in STEM fields and the adoption of Information and Communication Technology (ICT) in educational practice. Xueshu also holds a Master's degree from the LBJ School of Public Affairs, focusing on post-secondary education policy development and program evaluation.

Address: 1616 Guadalupe St, School of Information, University of Texas at Austin, Austin, TX 78701 Phone: 512-810-1638 Email: xueshu_chen@utexas.edu 


\title{
What have we learned from a systematic review of literature on Hispanic transfer students in engineering?
}

\begin{abstract}
This paper describes preliminary results of a literature search. The purpose of our study is to synthesize all of the relevant prior work regarding Hispanic students matriculating through twoyear to four-year institutions and completing engineering bachelor's degrees. The approach we are using to identify and synthesize the articles is systematic review methodology. Systematic review is a set of methodologies to identify relevant primary studies (e.g., journal articles, technical reports, conference papers) from multiple sources and synthesize results from these studies. The inclusion criteria we have defined for the articles we will synthesize are: (1) provides a clear definition of how student success was defined, e.g., transfer, retention, graduation, intent to complete degree; (2) presents empirical evidence of at least one individual or contextual factor that contributes to success of students at two-year institutions or who have transferred from a two-year to a four-year institution in the United States; (3) presents results or comparison of Hispanic students, Hispanic-serving institutions, or STEM students; and (4) published as a report, article, conference paper, or dissertation in English.
\end{abstract}

This study emphasizes Hispanic transfer students in engineering for several reasons. Firstly, representation of Hispanics in engineering careers is well below their significant and growing proportion of the U.S. population. Secondly, although substantial research has identified cultural and socioeconomic challenges that Hispanic students are facing, there is a dearth of large scale and/or quantitative work focusing on Hispanic students in engineering disciplines. Lastly, few (if any) systematic studies of effective interventions for Hispanic transfer engineering students exist.

The intent of our study is to identify articles that have addressed Hispanic transfer students and synthesize results from the collected set. At present, we are still identifying articles that would support our study. This paper describes early results from the literature search to provide an overview of that has been found.

\section{Introduction}

To prepare more than one million additional science, technology, engineering and mathematics (STEM) professionals for the U.S. workforce over the next decade, more emphasis must be placed on improving pathways for all students [1], particularly ethnic and racial minorities who have been historically underserved by higher education [2]. Prior work has shown that various underrepresented racial/ethnic student populations in STEM need to be studied separately and specifically, because these groups differ in higher education access and vertical transfer patterns [3]. We have focused this project on Hispanic STEM transfer students for multiple reasons. Firstly, representation of Hispanics in STEM careers is well below their significant and growing proportion of the U.S. population. Secondly, although substantial research has identified cultural and socioeconomic challenges facing Hispanic students in higher education, much less is known about Hispanic STEM students, and virtually no large scale studies have specifically studied Hispanic STEM transfer students. Thirdly, few systematic studies of effective interventions for Hispanic STEM transfer students exist. Programs such as summer bridge programs, mentoring, 
tutoring, learning communities, and other activities are fairly common at the undergraduate level in STEM fields, and many of these programs have historically been funded by NSF STEP and SSTEM programs. Few systematic studies of interventions have been conducted, however. Local assessment data, typically published in conference papers and reports, support the efficacy of these interventions; however, no systematic reviews of the considerable literature have been found. To significantly and positively impact representation of Hispanic scientists and engineers, we need a comprehensive synthesis to (a) develop patterns of successes and failures of Hispanic STEM transfer students and (b) identify factors related to effectiveness of interventions to promote transfer, retention and graduation of Hispanic STEM undergraduates. Given the urgency to improve transfer of Hispanic students to four-year engineering programs, the likelihood of largescale programs to improve the success of minority students in STEM, and the lack of comprehensive syntheses, the need for such syntheses is imminent and important. Therefore, we propose to develop a comprehensive framework for promoting success of Hispanic STEM transfer students by applying established systematic review methods [4] to existing primary studies in several areas. Results of the synthesis will be extensively shared with multiple stakeholders in the success of Hispanic STEM transfer students. The research question guiding this systematic review is:

What student and contextual characteristics and interventions have prior studies identified as supporting successful transfer and STEM bachelor's degree completion of Hispanic students who matriculate at two-year institutions?

\section{Research Methodology: Systematic Review}

Our proposed approach will provide a comprehensive review of existing primary studies through systematic review methodology, specifically a qualitative synthesis of quantitative, qualitative and mixed methods primary studies. Systematic review is a set of methodologies to identify relevant primary studies (e.g., journal articles, technical reports, conference papers) from multiple sources and synthesize results from these studies. We are following established guidelines for conducting a systematic review $[4,5]$.

\section{Results from a Preliminary Literature Search}

An initial literature search of the ERIC database was conducted using the following search string:

( DE "Hispanic American Students" OR DE "Hispanic Americans" OR AB( hispanic* or latin*) AND ( ( DE "Two Year College Students" OR DE "Two Year Colleges" ) OR $\mathrm{AB}(($ "two year" or community or technical or vocational or junior) near/1 college*) )

ERIC was chosen as the first database to search, because it was thought to provide the largest number of articles on education. The search yielded 1207 citations. As work on the project continues, we will use other search strings and expand the search to other databases. Some of the papers will be duplicates of the citations found in the initial search, but many others will be new citations. Given the extensive list of citations that have been found with this initial search it is helpful to summarize what has been found thus far. 
Table 1 shows that the most common citations were reports, which include reports on community colleges at the state and district levels as well as reports from individual institutions. Journal articles were the second most common type of citation, followed by entire books and dissertations and a small number of conference papers.

Table 1. Types of Citations found in the ERIC Database Search

\begin{tabular}{|l|r|r|}
\hline Type & Number & Percentage \\
\hline Report & 849 & $70.34 \%$ \\
\hline Journal Article & 228 & $18.89 \%$ \\
\hline Book & 85 & $7.04 \%$ \\
\hline Dissertation & 39 & $3.23 \%$ \\
\hline Conference & 6 & $0.50 \%$ \\
\hline Total & 1207 & $100.00 \%$ \\
\hline
\end{tabular}

Over $70 \%$ of the citations found in the initial literature search were reports. One hundred thirty of the 849 reports were state level reports on the community college system in the state. California, given its large system of community college, provides the largest percentage of state reports. California is followed by Florida, Illinois, and Washington. Together, these four states provided over $75 \%$ of the state reports. Although there are exceptions, state reports tend to focus on student enrollment demographics (e.g., gender, race/ethnicity, age, part-time/full-time, credit/non-credit), enrollment projections, and financial issues.

Table 2. Reports by State

\begin{tabular}{|l|r|r|}
\hline State & Number & Percentage \\
\hline California & 43 & $33.58 \%$ \\
\hline Florida & 29 & $22.31 \%$ \\
\hline Illinois & 17 & $13.08 \%$ \\
\hline Washington & 11 & $8.46 \%$ \\
\hline Connecticut & 8 & $6.15 \%$ \\
\hline North Carolina & 3 & $2.31 \%$ \\
\hline Oklahoma & 3 & $2.31 \%$ \\
\hline Colorado & 3 & $2.31 \%$ \\
\hline Arizona & 3 & $2.31 \%$ \\
\hline New Jersey & 2 & $1.54 \%$ \\
\hline Nevada & 2 & $1.54 \%$ \\
\hline Texas & 1 & $0.77 \%$ \\
\hline Massachusetts & 1 & $0.77 \%$ \\
\hline New York & 1 & $0.77 \%$ \\
\hline Total & 130 & $100.00 \%$ \\
\hline
\end{tabular}

Single institution reports provide another large segment of the reports with 217. Table 3 shows the most frequent institutions. Miami-Dade Community College contributed the most single institution reports. 
Table 3. Most Frequent Institutional Reports

\begin{tabular}{|l|r|}
\hline Institution & Number \\
\hline Miami-Dade Community College & 71 \\
\hline College of the Canyons & 14 \\
\hline City College of San Francisco & 11 \\
\hline Piedmont Virginia Community College & 9 \\
\hline Westchester Community College & 8 \\
\hline Houston Community College & 8 \\
\hline Northern Virginia Community College & 7 \\
\hline Los Angeles City College & 7 \\
\hline Community College of Philadelphia & 5 \\
\hline St. Petersburg Junior College & 5 \\
\hline Hudson County Community College & 5 \\
\hline Cabrillo College & 4 \\
\hline Prince George's Community College & 4 \\
\hline San Antonio College & 4 \\
\hline Austin Community College & 4 \\
\hline
\end{tabular}

Analyzing the articles by year published can provide some indication of the importance of the issue. As shown in Figure 1, there was very little published before 1977. After 1977, the number of articles published on Hispanic students at two-year institutions increased until 1991. During the 1990s, the number of articles decreased until a significant spike in 2000-2002. From 1997-2014, larger numbers of articles annually published tend to be at the beginning of decades, perhaps as reports on the past decade are published. 


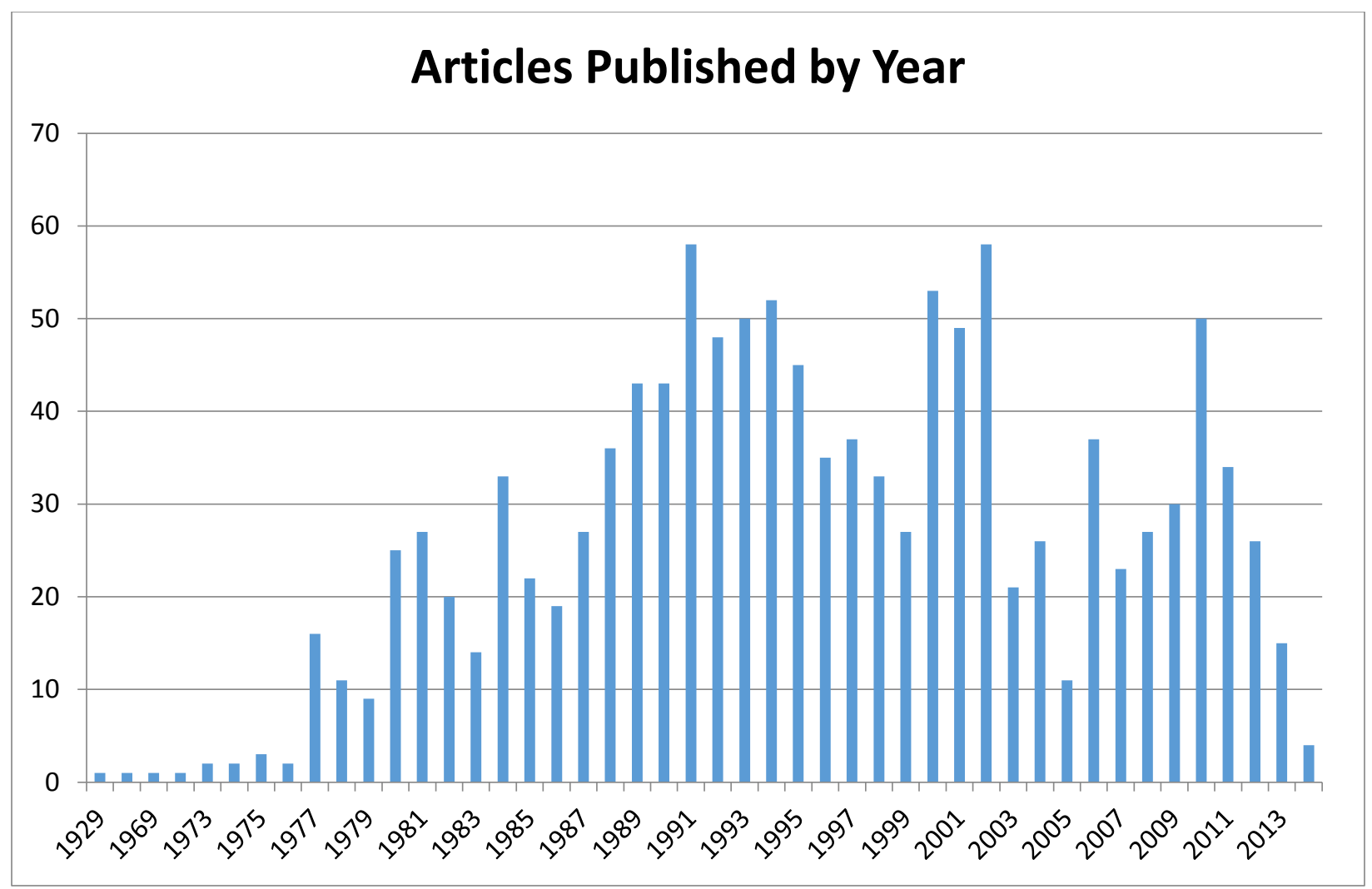

Figure 1. Articles Published Each Year

\section{Discussion}

We are at one of the earliest phases of this systematic review. Since we are not yet focusing on engineering-specific publications, this literature is relatively new to us and may be new to other ASEE members. Our search of just one database yielded over 1000 citations. However, many of these, particularly the oldest ones, did not meet our inclusion criteria. The inclusion criteria we have defined are: (1) provides a clear definition of how student success was defined, e.g., transfer, retention, graduation, intent to complete degree; (2) presents empirical evidence of at least one individual or contextual factor that contributes to success of students at two-year institutions or who have transferred from a two-year to a four-year institution in the United States; (3) presents results or comparison of Hispanic students, Hispanic-serving institutions, or STEM students; and (4) published as a report, article, conference paper, or dissertation in English. We found many state and institution-level reports that focused on student characteristics, including graduation or transfer rates. However, most of these did not describe specific interventions or factors in detail, and if they did, there was no empirical evidence to support arguments of efficacy. Nonetheless, we have identified a number of citations that will be examined more closely in later phases of the project which we anticipate will yield important insights about factors that contribute to the success of Hispanic STEM transfer students. 


\section{Conclusions}

Our paper has presented preliminary results from a search of the ERIC database for articles on factors influencing the success of Hispanic students who start at two-year institutions and transfer to four-year institutions. In addition, our project intends to study interventions that have been implemented to improve the success of students in transferring as well as results from these interventions. Our paper has attempted to characterize the literature base that is available to support the study. Further, as a part of the study, we are actively seeking nominations of prior studies and ongoing projects from the community that would be appropriate to include in the synthesis.

While the intent of our particular systematic review is to study Hispanic engineering students who completed their four-year engineering degree after transferring from a two-year institution, the methodology described in this paper [6] can used for multiple other purposes.

\section{Acknowledgements}

This work was funded by the US National Science Foundation Division of Undergraduate Education through grant numbers 1446319, 1446323 and 1446369. Any opinions, findings, and conclusions or recommendations expressed in this material are those of the authors and do not necessarily reflect the views of the National Science Foundation.

\section{Bibliographic Information}

1. Olson, S. and D.G. Riordan, Engage to excel: Producing one million additional college graduates with degrees in science, technology, engineering, and mathematics. Report to the President. 2012, Executive Office of the President, President's Council of Advisors on Science and Technology: Washington, DC, USA.

2. Rendon, L.I. and J.R. Valadez, Qualitative indicators of Hispanic student transfer. Community College Review, 1993. 20(4): p. 27-37.

3. Hagedorn, L.S., et al., Transfer Between Community Colleges and 4-Year Colleges: The All American Game. Community College Journal of Research and Practice, 2006. 30(3): p. 223-242.

4. Gough, D., S. Oliver, and J. Thomas, eds. An introduction to systematic reviews. 2012, Sage Publications, Ltd.: London, UK.

5. Petticrew, M. and H. Roberts, Systematic reviews in the social sciences: A practical guide. 2006, Malden, MA: Blackwell Publishing.

6. Borrego, M., M.J. Foster, and J.E. Froyd, Systematic literature reviews in engineering education and other developing interdisciplinary fields. Journal of Engineering Education, 2014. 103(1): p. 45-76. 